\title{
Analytical and Experimental Study Using Output-Only Modal Testing for On-Orbit Satellite Appendages
}

\author{
Mashiul Alam, ${ }^{1}$ Ramin Sedaghati, ${ }^{1}$ Yvan Soucy, ${ }^{2}$ and Rama B. Bhat ${ }^{1}$ \\ ${ }^{1}$ Department of Mechanical and Industrial Engineering, Concordia University, Montreal, Qc, Canada H3G 1 M8 \\ ${ }^{2}$ Canadian Space Agency, Space Technologies, John H. Chapman Space Center, Saint-Hubert, Qc, Canada J3Y $8 Y 9$
}

Correspondence should be addressed to Ramin Sedaghati, sedagha@encs.concordia.ca

Received 8 May 2008; Revised 20 January 2009; Accepted 25 February 2009

Recommended by Samir Gerges

Output-only modal testing is an effective technique to identify the modal parameters of structural systems under ambient or operational conditions and has potential applications in civil, mechanical, and aerospace engineering. It may effectively be used for model validation, model updating, quality control, and health monitoring through the determination of modal characteristics of the structures. This approach to modal testing has great potential for ground and on-orbit modal testing of space hardware, especially for flexible structures such as membrane payloads where the operating and ambient excitations, such as firing of AC thrusters and ambient thermal shock, are difficult or impossible to measure. The main objective of this work is to conduct analytical and experimental study on output-only modal testing and to demonstrate its potential application to effectively extract modal parameters of an on-orbit satellite appendage.

Copyright ( 2009 Mashiul Alam et al. This is an open access article distributed under the Creative Commons Attribution License, which permits unrestricted use, distribution, and reproduction in any medium, provided the original work is properly cited.

\section{Introduction}

The concept of output-only modal testing is not new but the development of this technique has a brief history. For quite some time people working in modal analysis have been performing output-only modal identification using the commonly accepted fact that if only one mode contributes to a certain band of the cross-spectral matrix, then any row or column in that matrix can be used as a mode shape estimate. By picking a peak in one of the spectral density functions one can get the mode shape from one of the columns or rows in the cross-spectral matrix. This classical approach, also known as Basic Frequency Domain (BFD) technique, is based on the simple signal processing technique using a discrete Fourier transform and hinges on the fact that wellseparated modes can be estimated directly from the matrix of the cross-spectra [1].

In the case of closely spaced modes, it can be difficult to detect the modes and, even in the case where close modes are detected, estimated frequencies and mode shapes become heavily biased. Furthermore, the estimated frequencies are limited by the frequency resolution of the estimated spectral density and, in all cases, damping estimation is uncertain or impossible.

The first time-domain technique that really became known for serious output-only identification was introduced by Ibrahim and Milkulcik [2-4] and is known as the Ibrahim Time Domain (ITD) method. Shortly after that the polyreference time-domain method was introduced by Vold et al. [5] and Vold and Rocklin [6]. The Eigen Realization Algorithm (ERA) was developed by Juang and Pappa [7] and later employed in space application $[8,9]$. The last two techniques, that is, Polyreference and ERA, use multiple inputs but ITD can also be formulated as a multiple input method as described by Fukuzono [10]. Recently, Zhang et al. [11] gave a common formulation for all these techniques. What they have in common is that they assume that a free response function can be obtained. These time domain techniques are all based on a function represented by exponential decay. A more modern time-domain technique called Stochastic Subspace Identification (SSI) has also been introduced. Three different implementations of Stochastic Subspace Identification technique are: Unweighted Principal Component (UPC), Principal Component (PC), and 
Canonical Variate Analysis (CVA). These methods are time domain methods that directly work with time domain data, without any conversion to spectral functions. The algorithm for this new stochastic subspace time domain technique was described by Van Overschee and De Moor [12-15]. Also, more detailed information on stochastic subspace method can be found in [16-19]. Two simulation examples including a spring-mass-system and a horizontal cantilever beam in transverse vibration were demonstrated by Lardies [20] to investigate the efficiency of this stochastic subspace method.

The main advantage of the classical, that is, BFD approach is that the structural properties can be easily found just by examining the density functions. The disadvantages associated with this approach are removed by another method called Frequency Domain Decomposition technique (FDD) that was extensively investigated by Rent and Zong [21] and Brincker et al. [22-24]. This method contains all the advantages of the classical technique and also provides clear indication of harmonic components in the response signal. It has been described that the spectral matrix can be decomposed with the Singular Value Decomposition (SVD) method into a set of auto-spectral density functions, each corresponding to a Single Degree of Freedom (SDoF) system. The FDD technique can effectively handle close modes and noise; however it cannot provide damping information. The Enhanced Frequency Domain Decomposition (EFDD) is basically an extension of the FDD technique capable of providing damping information. In EFDD, the identified frequency function around each resonant peak is transferred back to the time domain using Inverse Discrete Fourier Transform, and damping can be obtained by the logarithmic decrement of the corresponding SDoF normalized autocorrelation function.

Abdelghani et al. [25] presented the results of the performance of output-only identification algorithm for modal analysis of aircraft structures under white noise excitation. It was found that the subspace-based algorithm performs well.

The PolyMAX is a further evolution of the so-called Least-Square Complex Frequency (LSCF) domain method. Originally, LSCF was introduced to find initial values of the iterative maximum likelihood method [26]. The method estimates a so-called common-denominator transfer function model [27]. The most important advantage of LSCF estimator over the available and widely applied parameter estimator techniques [28] is that it provides very clear stabilization diagrams. A thorough analysis of different variants of the common-denominator LSCF method can be found in [29]. A complete background on frequency-domain system identification can be found in [30].

The main aim of the project is to provide some insight into the application of the ouput-only modal testing for on-orbit satellite appendages. In this work the performance of different out-put only modal testing techniques will be examined both analytically and experimentally on a simple plate type structure under different environmental excitations. Then a solar panel appendage under representative operational conditions will be simulated to identify its modal parameters using different output-only modal testing techniques. In the following sections dynamics of the

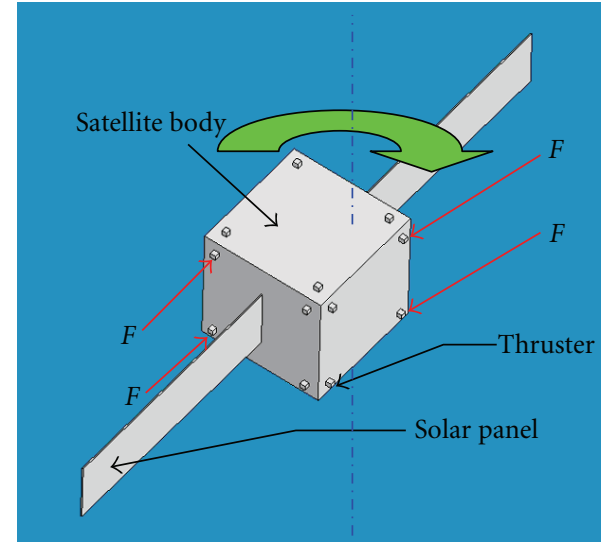

Figure 1: Simple model of a satellite.

spacecraft appendages will first be discussed. This will be followed by the experimental and analytical investigation on modal parameter identification of a simple plate structure extracted by different output-only modal testing techniques. Finally a plate type structure representing the solar panel appendages of the Communication Technology Satellite (CTS) will be simulated to identify its modal parameters using different output-only modal testing techniques.

\section{Dynamics of Spacecraft Appendages}

The appendages of a spacecraft consist of lightweight, flexible, deployable members in the form of solar panels, antennas, and booms. Satellites have to carry their own power source because they cannot receive power from earth and they must remain pointed in a specific direction, or orientation, to accomplish their mission. Maintaining proper orientation is typically accomplished by small rocket engines, known as attitude thrusters. These thrusters/attitude controllers perform some functions such as pointing the antennas in a desired direction, pointing solar panels toward the sun, keeping sensors and sensitive equipment away from the sun's light and heat, and pointing the control jets in the desired direction to accomplish efficient maneuvers [31].

Attitude thrusters can make large changes to orientation quickly and can create significant vibration in the satellite body. They are the largest source of torque on the spacecraft. If they are used to achieve accurate pointing, small amount of torque should be applied as consistent impulses for minimum switch-on time of several milliseconds [31, 32].

Figure 1 represents the simple model of satellite during attitude control. The satellite body rotates due to the torque created by the forces exerted by the thrusters.

Spacecraft thrusters may be categorized into cold-gas and hot-gas thrusters. Cold-gas thrusters produce small amount of thrust, typically $5 \mathrm{~N}$ or less and are useful for small spacecraft and for fine attitude control; whereas the hot-gas thrusters can produce thrusts from as low as $0.5 \mathrm{~N}$ up to $9000 \mathrm{~N}$, but are usually used for higher thrust applications [33]. The excitation may exist for approximately 10-15 seconds including steady-state thrust for $4 \sim 5$ seconds. 
TABLE 1: Material and geometrical characteristics of the test plate article.

\begin{tabular}{lc}
\hline Material type & Aluminum $6061-\mathrm{T} 6$ \\
\hline Modulus of Elasticity, $E$ & $68.7 \times 10^{9} \mathrm{~N} / \mathrm{m}^{2}$ \\
Length of the test article, $a$ & $1.22 \mathrm{~m}$ \\
Width of the test article, $b$ & $0.3048 \mathrm{~m}$ \\
Thickness of the test article, $h$ & $0.00635 \mathrm{~m}$ \\
Density, $\rho$ & $2.71 \times 10^{3} \mathrm{~kg} / \mathrm{m}^{3}$ \\
Poisson's ratio, $v$ & 0.3 \\
\hline
\end{tabular}

The analytical investigation of the structural dynamics of a flexible solar array had been done by Vigneron et al. [34]. The analysis focused on two representative array units of the Communication Technology Satellite (CTS) employed in ground-test program. Frequencies and mode shapes were identified by (a) Rayleigh-Ritz method on a simplified continuum model and by (b) NASTRAN finite-element program. Extrapolation of modal information to on-orbit conditions has also been discussed. The formulation of complex system dynamics due to interactions between librational motion, transverse vibration, and thermal deformations has been elaborated in [35].

\section{Analytical and Experimental Modal Parameter Identification of a Cantilever Aluminum Plate Using Output-Only Modal Testing}

In this project the analytical and experimental study has been conducted on a cantilever aluminum plate type structure representing the solar panel. The dimensions of the plate are selected so that the fundamental frequency of the plate to be in the practical range of $3-4 \mathrm{~Hz}$. The material and geometrical properties of the experiment test article are presented in Table 1.

Using Table 1, the plate is modeled in finite-element software PATRAN/NASTRAN, and its first four natural frequencies are found to be: $3.51 \mathrm{~Hz}$ (1st bending), $22.00 \mathrm{~Hz}$ (2nd bending), $28.33 \mathrm{~Hz}$ (1st Torsion), and $61.90 \mathrm{~Hz}$ (3rd bending). As it can be seen, the fundamental frequency is in the practical range of interest.

Experiments have been carried out under both base and single point excitations using facilities in Vibration lab of the Canadian Space Agency (CSA) in Saint-Hubert, QC, Canada. The experimental data are acquired using LMS Test Lab software and processed for modal information using LMS PolyMAX (for reference modal parameters), LMS Operational PolyMAX, and also B\&K operational PULSE software. The results are presented and discussed hereafter. Vibration measurements are done on the test fixture at first to find out its natural frequencies, and to see whether the fixture remains rigid in the frequency range of interest in the tests.

The schematic of the test setup is presented in Figure 2. The test article is placed vertically on the slip table of a shaker using a fixture for both base and point excitation. The shaker

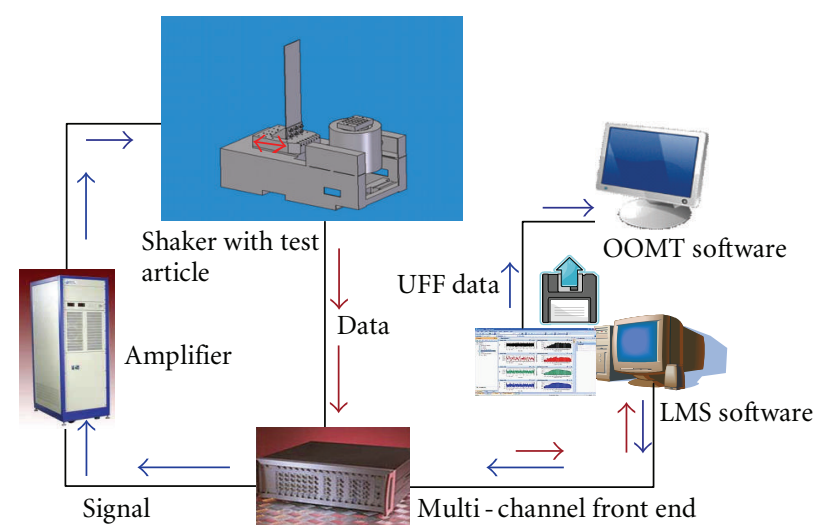

FIGURE 2: Schematic diagram of the test set-up.

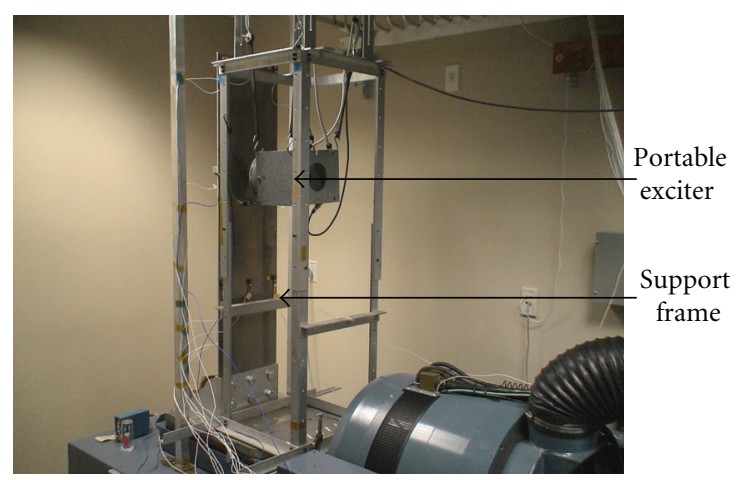

FIgURE 3: Test-setup for point excitation.

is used to perform the driven base excitation; whereas a single point portable exciter suspended on a frame and attached to the test article at the front centre mid-point using a force sensor, and a stinger is used to conduct point excitation experiment as shown in Figure 3. The accelerometers are glued on the test article and connected to the front end of the modal system through cables. With the help of PolyMAX, the data is processed to identify the modal parameters from the frequency response functions. For the case of base excitation, the response acceleration over input acceleration (transmissibility) is evaluated; whereas for the case of point excitation response acceleration over input force (FRF) is evaluated. Also, using cross-power densities of the processed data, the modal parameters are extracted with the help of operational PolyMAX. Finally, time series data are exported in universal file format to be processed in PULSE operational modal analysis software to extract the modal parameters.

For the case of base excitations, 9 accelerometers are attached on the test article. Eight are attached on the front face at points $1,2,3,4,6,7,8$, and 9 , and one accelerometer is attached at the center of the plate on the back (point $5 b$ ) as shown in Figure 4.

For the case of point excitations, 9 accelerometers and a force sensor are attached on the test article. Accelerometers are located at the same locations as for the driven base excitation on the front face of the plate (except at point 5 


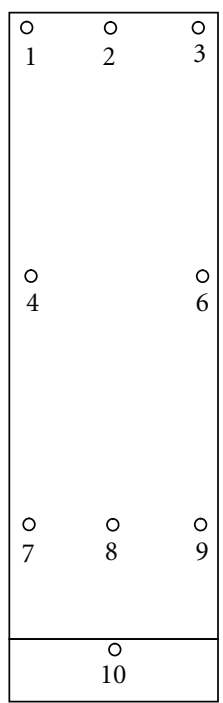

(a)

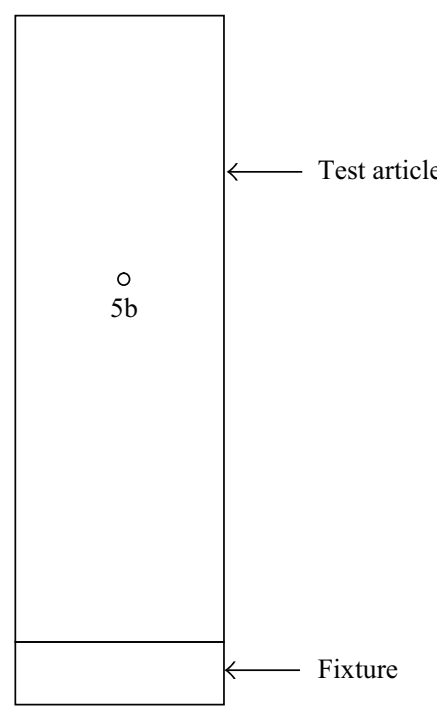

(b)
Figure 4: Accelerometer locations at (a) front face (b) back face of test article and fixture for base excitation.

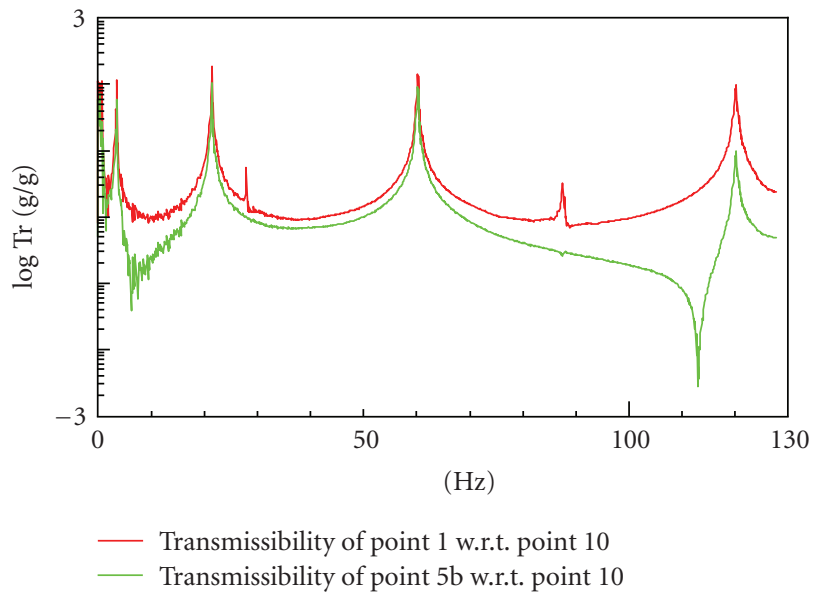

FIGURE 5: Sample transmissibilities for driven base run.

where it is on the back face) and also a force sensor and a portable exciter are connected to point 5 on the front face. It should be noted that although an excitation location on either side of the plate (e.g., point 4) would have been a better choice for exciting the torsion modes, point 5 on the centerline of the plate was selected in order to have similar capability (or lack of it) of exciting torsion modes as driven base excitation.

It should be noted that for computation of the crossspectra required in Operational PolyMAX, the reference accelerometer sensor was located on top corner of the plate (back of point 1) for both cases of driven base and portable exciter tests. As a general guideline for selection of the set of references for computing the cross-spectra, one should select the response locations (and directions) that correspond to maximum displacement for the key modes of interest. Operational PULSE software computed a

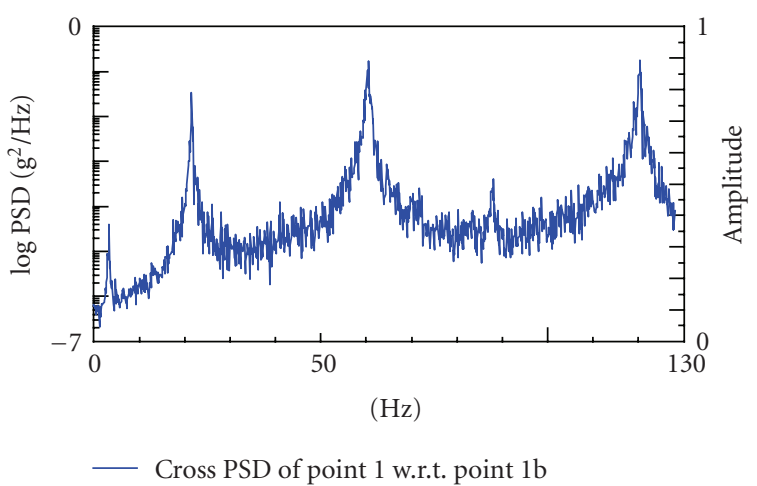

FIgURE 6: Sample cross PSD for the driven base excitation.

complete cross-spectra matrix using all response locations as references. It is noted that the reference modal parameters are identified using PolyMAX from evaluation of transmissibility and FRF for the cases of driven base and portable exciter tests, respectively. Reference sensors have been located on the upper part of the fixture (point 10 in Figure 4) for driven base case and at point 5 on the front face of test article for case of point excitation.

The parameters that are considered for both the driven base excitation and point excitation methods are presented in Table 2.

It should be noted that for the driven base test, the experimental runs are open-loop, and hence the random input signals mentioned in Table 2 are uncontrolled and do not follow a predefined profile as for a typical vibration control setup. This is a driven base modal test, not a vibration test.

3.1. Fixture Survey. At the beginning of the experiment a transmissibility-based modal survey was carried out on the fabricated fixture to ensure that the fixture is rigid enough in the frequency range of interest. The fixture was rigidly mounted to the slip table through 6 bolts. Ten accelerometers are mounted on the fixture, and a reference accelerometer is placed at the end side of the slip table. The first and second modes of the fixture are found to be $55 \mathrm{~Hz}$ and $157 \mathrm{~Hz}$. As it can be seen the fundamental frequency of the fixture $(55 \mathrm{~Hz})$ is well above the first 3 natural frequencies of the test article which are about $3.48 \mathrm{~Hz}, 21.54 \mathrm{~Hz}$, and $28.15 \mathrm{~Hz}$. In fact, this confirms that the fixture dynamics have negligible effects on the dynamics of the test article for at least the first three modes of the test article. For the higher modes, since the reference modal parameters were also obtained experimentally, any effects that the fixture might have in the modal parameters would be present for both the reference data and the data processed with the output-only techniques.

3.2. Experimental Results-Base Excitation. The natural frequency and modal damping factors (damping ratios) of the test article are first identified using traditional modal analysis approach by processing the transmissibility with 


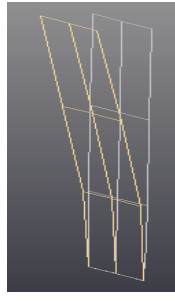

1st mode

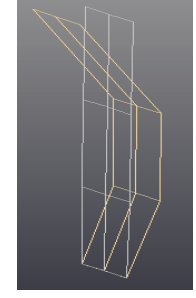

2nd mode

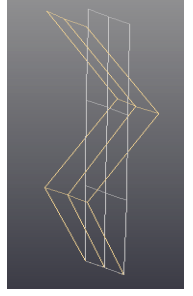

4th mode

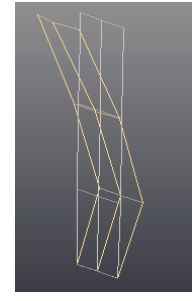

6 th mode
FIGURE 7: Mode shapes from output-only approaches for driven base run.

PolyMAX. These modal parameters are to be used as reference for comparison with the values extracted with operational modal techniques. Figure 5 shows two samples of trasnsmissibilities measured from the driven base excitation.

The upper curve in Figure 5 represents the transmissibility at the point 1 location on test article; whereas the lower curve represents the transmissibility at the point $5 \mathrm{~b}$ at the back face of the test article as shown in Figure 4. It is noted that upper curve shows some torsion peaks at about $28 \mathrm{~Hz}$ and $87 \mathrm{~Hz}$ but the lower curve does not show the torsion modes as point 5 is located at the centerline along the length of the test article.

To identify modal parameters both Operational PolyMAX and Pulse operational software are used. It is noted that the cross power spectras are required in Operationl PolyMAX to identify the modal parameters, while for the PULSE operational methods (FDD, EFDD, SSI), time series output data should be extracted. An example of the cross power spectra for base excitation run is presented in Figure 6.

Natural Frequencies and damping ratios for the first six modes extracted using FRF PolyMAX (reference), Operation PolyMAX and PULSE are tabulated in Tables 3 and 4, respectively.

It can be seen that very good agreement exists between operational modal results and reference modal parameters. As it can be seen from Tables 3 and 4, no modal parameters could be extracted for mode 3 (1st torsional mode) using both operational Polymax and Operational Pulse methods. Also operational Polymax was not able to detect the fifth mode (2nd torsional mode) while most PULSE operational methods were able to identify the modal parameters for the fifth mode. The FDD method does not provide damping information. It should be noted that driven base excitation mainly excites bending modes in symmetric structures and thus it is not surprising that operational methods which are based on only output responses have difficulty to detect torsional modes.

The mode shapes for driven base runs using output-only modal testing technique are shown in Figure 7. Mode shapes obtained from PolyMAX using transmissibility, Operational PolyMAX, and PULSE output-only modal testing are close to each other except for the 3rd and 5th modes in Operational PolyMAX and 3rd mode in PULSE, which are missing. It should be noted that the translational base excitation could

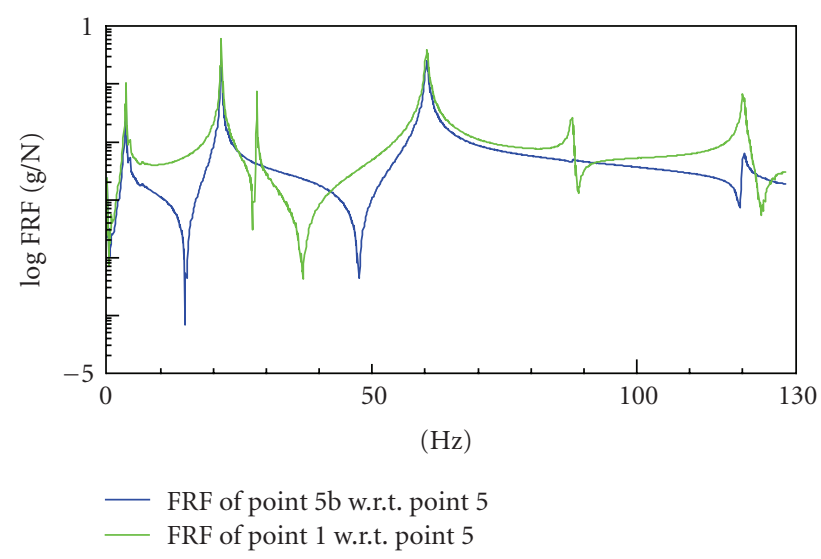

FIgURE 8: Sample FRFs for point excitation run.

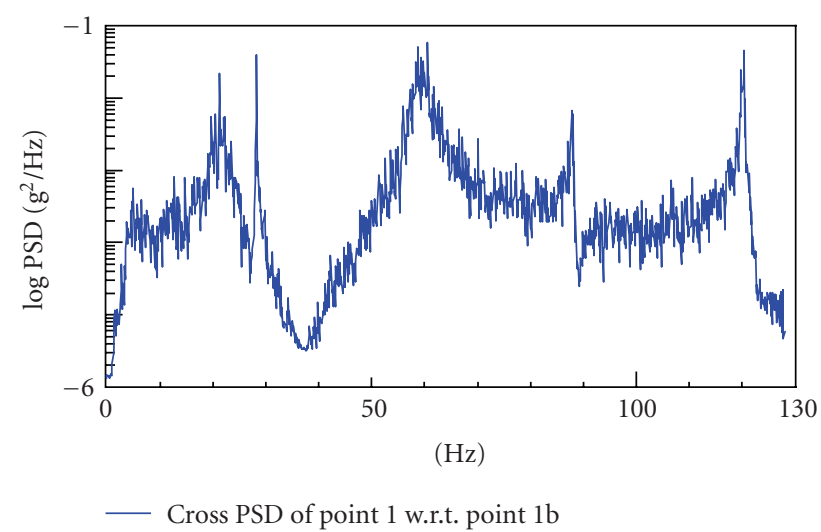

FIGURE 9: Sample cross PSD for portable excitation run.

not excite well the torsional modes of the test article, as may be expected.

3.3. Experimental Results-Single Point Excitation. Sample FRFs for similar points (points 1 and 5b) discussed in driven base case are shown in Figure 8. As discussed before, these FRFs will be processed by PolyMAX to extract modal parameters which will be used as reference values for comparison with those obtained from operational testing.

As it can be seen from Figure 8, FRF at point 1 contains torsional mode peaks as expected.

As mentioned before, for Operational PolyMAX, the cross power spectra are used to identify the modal parameters. A sample of cross-power spectra for point excitation run is shown in Figure 9.

The identified natural frequencies and damping factors using output-only modal testing approaches for this case are provided in Tables 5 and 6 , respectively.

It can be seen that there is close agreement in the values of natural frequencies identified using the different outputonly modal testing approaches with those of reference FRF except for the first mode. The reason for this discrepancy for the identified fundamental mode can be attributed to the fact that the fundamental mode found by operational techniques 
TABle 2: Parameters for both driven base excitation and point excitation.

\begin{tabular}{lccc}
\hline Method & PolyMAX & Operational PolyMAX & PULSE \\
\hline Bandwidth & $128 \mathrm{~Hz}$ & $128 \mathrm{~Hz}$ & $128 \mathrm{~Hz}$ \\
No. of frequency lines & 1025 & 1025 & 8192 \\
No. of averages & 30 & 15 (portable) and 10 (base excitation) & 22 \\
Signal type & $75 \%$ burst random & $100 \%$ random & $100 \%$ random \\
\hline
\end{tabular}

TABLE 3: Natural frequencies of test article under base excitation.

\begin{tabular}{lllccccc}
\hline Mode & $\begin{array}{l}\text { Transmissibility } \\
\text { PolyMAX } \\
(\text { Ref. } f(\mathrm{~Hz})\end{array}$ & $\begin{array}{l}\text { Operational } \\
\text { PolyMAX } f(\mathrm{~Hz})\end{array}$ & FDD $f(\mathrm{~Hz})$ & EFDD $f(\mathrm{~Hz})$ & $\begin{array}{c}\text { PULSE methods } \\
\text { UPC } f(\mathrm{~Hz})\end{array}$ & $\begin{array}{c}\text { PC } f(\mathrm{~Hz}) \\
\text { CVA } f(\mathrm{~Hz})\end{array}$ \\
\hline 1 & 3.48 & 3.35 & 3.45 & 3.45 & 3.46 & 3.46 \\
2 & 21.54 & 21.49 & 21.38 & 21.50 & 21.53 & 21.52 \\
3 & 28.15 & - & - & - & - & - & -6.46 \\
4 & 60.43 & 60.39 & 60.5 & 60.49 & 60.52 & 60.45 \\
5 & 87.84 & - & 87.75 & 87.77 & 87.77 & 87.77 & 87.69 \\
6 & 120.5 & 120.29 & 120.6 & 120.4 & 120.5 & 120.4 \\
\hline
\end{tabular}

TABLE 4: Damping ratios of test article under base excitation.

\begin{tabular}{|c|c|c|c|c|c|c|c|}
\hline \multirow{3}{*}{ Mode } & \multirow{3}{*}{$\begin{array}{l}\text { Transmissibility } \\
\text { PolyMax (Ref.) } \xi(\%)\end{array}$} & \multirow{3}{*}{$\begin{array}{l}\text { Operational } \\
\text { PolyMax } \xi(\%)\end{array}$} & \multicolumn{5}{|c|}{ PULSE methods } \\
\hline & & & FDD $\xi(\%)$ & EFDD $\xi(\%)$ & & SSI & \\
\hline & & & (10) & (1) & UPC $\xi(\%)$ & $\mathrm{PC} \xi(\%)$ & CVA $\xi(\%)$ \\
\hline 1 & 0.40 & 1.43 & - & 0.59 & 0.78 & 0.59 & 0.84 \\
\hline 2 & 0.14 & 0.28 & - & 0.39 & 0.23 & 0.21 & 0.23 \\
\hline 3 & 0.02 & - & - & - & - & - & - \\
\hline 4 & 0.13 & 0.2 & - & 0.19 & 0.27 & 0.33 & 0.34 \\
\hline 5 & 0.20 & - & - & 0.24 & 0.24 & 0.33 & 0.34 \\
\hline 6 & 0.14 & 0.11 & - & 0.35 & 0.23 & 0.54 & 0.36 \\
\hline
\end{tabular}

TABLE 5: Natural frequencies of test article under point excitation.

\begin{tabular}{|c|c|c|c|c|c|c|c|}
\hline \multirow{3}{*}{ Mode } & \multirow{3}{*}{$\begin{array}{l}\text { FRF PolyMax (Ref.) } \\
f(\mathrm{~Hz})\end{array}$} & \multirow{3}{*}{$\begin{array}{l}\text { Operational } \\
\text { PolyMax } f(\mathrm{~Hz})\end{array}$} & \multicolumn{5}{|c|}{ PULSE methods } \\
\hline & & & FDD $f(\mathrm{~Hz})$ & EFDD $f(\mathrm{~Hz})$ & & SSI & \\
\hline & & & & & UPC $f(\mathrm{~Hz})$ & $\mathrm{PC}(\mathrm{Hz})$ & CVA $f(\mathrm{~Hz})$ \\
\hline 1 & 3.47 & 4.98 & 4.85 & 4.60 & 4.60 & 4.75 & 4.84 \\
\hline 2 & 21.50 & 21.39 & 21.0 & 21.11 & 21.21 & 21.33 & 21.41 \\
\hline 3 & 28.26 & 28.25 & 28.25 & 28.31 & 28.28 & 28.28 & 28.28 \\
\hline 4 & 60.39 & 59.28 & 59.50 & 59.38 & 59.49 & 59.43 & 59.45 \\
\hline 5 & 87.84 & 87.91 & 87.75 & 87.78 & 87.81 & 87.81 & 87.81 \\
\hline 6 & 120.1 & 120.1 & 120.5 & 120.0 & 120.1 & 119.8 & 120.1 \\
\hline
\end{tabular}

TABLe 6: Damping ratios of test article under point excitation.

\begin{tabular}{|c|c|c|c|c|c|c|c|}
\hline \multirow{3}{*}{ Mode } & \multirow{3}{*}{$\begin{array}{l}\text { FRF PolyMax (Ref.) } \\
\xi(\%)\end{array}$} & \multirow{3}{*}{$\begin{array}{l}\text { Operational } \\
\text { PolyMax } \xi(\%)\end{array}$} & \multicolumn{5}{|c|}{ PULSE methods } \\
\hline & & & $\operatorname{FDD} \xi(\%)$ & EFDD $\xi(\%)$ & & SSI & \\
\hline & & & & & UPC $\xi(\%)$ & $\mathrm{PC} \xi(\%)$ & CVA $\xi(\%)$ \\
\hline 1 & 0.95 & 1.86 & - & 0.76 & 1.85 & 1.36 & 2.0 \\
\hline 2 & 0.21 & 0.44 & - & 0.26 & 1.87 & 2.51 & 2.23 \\
\hline 3 & 0.08 & 0.02 & - & 0.59 & 0.20 & 0.19 & 0.19 \\
\hline 4 & 0.34 & 0.74 & - & 1.96 & 1.60 & 1.96 & 1.95 \\
\hline 5 & 0.27 & 0.02 & - & 0.29 & 0.23 & 0.21 & 0.22 \\
\hline 6 & 0.22 & 0.11 & - & 0.37 & 0.26 & 0.36 & 0.29 \\
\hline
\end{tabular}




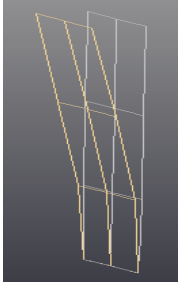

1st mode

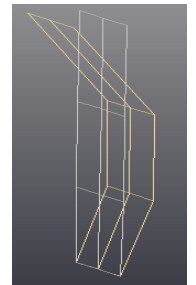

2nd mode

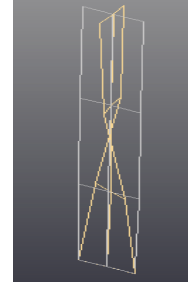

3rd mode

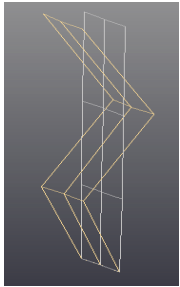

4th mode

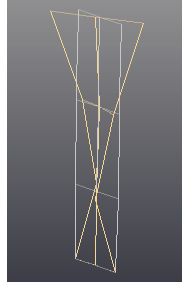

5th mode

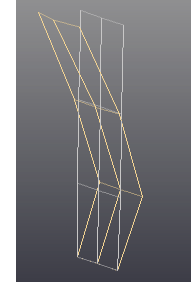

6th mode

Figure 10: Mode shapes from output-only approaches for point excitation.

TABle 7: Properties of solar panel and its dimensions.

\begin{tabular}{lc}
\hline Material type & Isotropic material \\
\hline Modulus of elasticity, $E$ & $207 \times 10^{9} \mathrm{~N} / \mathrm{m}^{2}$ \\
Length of the panel, $a$ & $6.48 \mathrm{~m}$ \\
Width of the panel, $b$ & $1.32 \mathrm{~m}$ \\
Thickness of the panel, $h$ & $0.0228 \mathrm{~m}$ \\
Density, $\rho$ & $0.1548 \times 10^{3} \mathrm{~kg} / \mathrm{m}^{3}$ \\
Poisson's ratio, $v$ & 0.3 \\
\hline
\end{tabular}

is basically related to the assembled structure and shaker due to the interaction between the test article and shaker.

It can also be observed that there are significant differences in the damping information due to the fact that the damping values are quite low, and it is more difficult to estimate them precisely.

The mode shapes identified for single-point excitation method using FRF curve fit are shown in Figure 10. Mode shapes identified by Operational PolyMAX and PULSE output-only modal testing are identical with the FRF modes. More details of the work and results are presented in [36].

\section{Simulation of Solar Panel}

As shown in Section 3, the output-only modal testing techniques could accurately identify the modal parameters of a plate structure under translational random driven base excitation. The Communication Technology Satellite (CTS) solar panel appendage is another example structure studied due to the simplicity of its boundary conditions and availability of some of its properties and characteristics [34]. The panel is $6.48 \mathrm{~m}$ long and $1.32 \mathrm{~m}$ wide. The materials used to manufacture these panels are glass-fibre with a Kapton layer on it. With the nominal thickness of such a panel, the fundamental frequency becomes very low. Normally, in the real solar panel structure of actual satellites, supports and stiffeners are used to increase the fundamental frequency of the appendages to about $3 \sim 4 \mathrm{~Hz}$. In the present study for design and analysis simplicity, the effects of stiffeners are smeared over the panel in order to reach the fundamental frequency of 3 to $4 \mathrm{~Hz}$. The panel is under base rotational excitation due to the torque created by the forces exerted by the thrusters.

The finite-element model of the panel consisting of 16 plate elements and 25 nodes (each node has two transla-

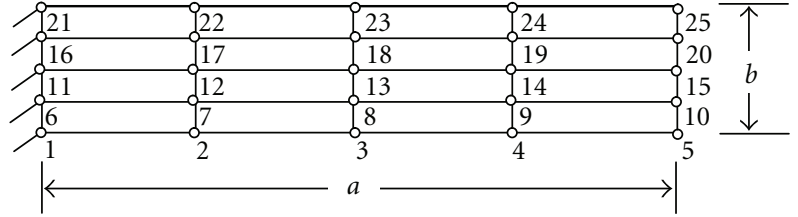

Figure 11: Finite-element model of the solar panel.

tional and one rotational degrees of freedom) modeled in PATRAN/NASTRAN is shown in Figure 11.

Material properties and dimensions of the solar panel are given in Table 7. As mentioned before, the real panels of actual satellites include stiffened elements which are very difficult to model and here for the sake of simplicity the effect of stiffeners is smeared in the plate. Thus the density is adjusted so that the resulting natural frequency is between the $3-4 \mathrm{~Hz}$ which is similar to that of real panel.

Rotational transient excitation is applied to the base of the solar panel, and the acceleration responses at all the nodes are evaluated. The damping ratio considered in this analysis is $2 \%$ for all modes. The transverse acceleration response at node 5 is evaluated. It is noted that the excitation time is 6 seconds and time step of 0.0025 seconds is considered for dynamic response.

The nodal transverse acceleration responses are transformed into a universal file format. This universal file is then processed in PULSE output-only modal testing software to extract the modal parameters of the solar panel. Here three different cases are investigated. Case 1: acceleration responses for all nodes are transferred into a universal file for further processing by operational PULSE modal testing software; Case 2: acceleration responses of just 4 nodes (node 3 , node 5, node 23, and node 25) are transferred; Case 3: acceleration response of just node 5 is transferred.

4.1. Extracted Modal Parameters Based on Case 1. The extracted natural frequencies of the solar panel using PULSE output-only modal testing techniques for Case 1 are tabulated in Table 8. There is close agreement between the identified natural frequencies and those obtained from finiteelement modal analysis. The identified damping ratios for Case 1 are also given in Table 9.

It should be noted that the damping ratios cannot be computed using FDD method. However EFDD and UPC methods were able to capture the damping factors. The reason that modal parameters could not be found by 
TABLE 8: Identified natural frequencies for Case 1.

\begin{tabular}{|c|c|c|c|c|c|c|}
\hline \multirow{3}{*}{ Mode } & \multicolumn{5}{|c|}{ Output-only modal testing methods } & \multirow{3}{*}{ Finite-element modal analysis $f(\mathrm{~Hz})$ (Reference) } \\
\hline & \multirow{2}{*}{ FDD $f(\mathrm{~Hz})$} & \multirow{2}{*}{$\operatorname{EFDD} f(\mathrm{~Hz})$} & \multicolumn{3}{|c|}{ SSI } & \\
\hline & & & $\mathrm{UPC} f(\mathrm{~Hz})$ & $\mathrm{PC} f(\mathrm{~Hz})$ & CVA $f(\mathrm{~Hz})$ & \\
\hline 1 & 3.125 & - & 3.30 & 3.0 & 3.25 & 3.24 \\
\hline 2 & 21.48 & 21.65 & 21.76 & - & 21.75 & 21.75 \\
\hline 3 & 68.75 & 68.25 & 68.72 & - & 68.78 & 68.22 \\
\hline 4 & 140.6 & 140.2 & 141.6 & - & 142.4 & 140.25 \\
\hline
\end{tabular}

TABle 9: Identified damping ratio for Case 1.

\begin{tabular}{|c|c|c|c|c|c|c|}
\hline \multirow{3}{*}{ Mode } & \multicolumn{5}{|c|}{ Output-only PULSE methods } & \multirow{3}{*}{ Finite-element modal analysis $\xi(\%)$ (Reference) } \\
\hline & \multirow{2}{*}{$\operatorname{FDD} \xi(\%)$} & \multirow{2}{*}{$\operatorname{EFDD} \xi(\%)$} & \multicolumn{3}{|c|}{ SSI } & \\
\hline & & & UPC $\xi(\%)$ & $\mathrm{PC} \xi(\%)$ & CVA $\xi(\%)$ & \\
\hline 1 & - & - & 2.1 & 2.4 & 3.3 & 2.0 \\
\hline 2 & - & 1.98 & 2.0 & - & 2.3 & 2.0 \\
\hline 3 & - & 1.99 & 2.0 & - & 1.96 & 2.0 \\
\hline 4 & - & 1.88 & 2.0 & - & 2.4 & 2.0 \\
\hline
\end{tabular}

TABLE 10: Identified natural frequencies for Case 2.

\begin{tabular}{|c|c|c|c|c|c|c|}
\hline \multirow{3}{*}{ Mode } & \multicolumn{5}{|c|}{ Output-only modal testing methods } & \multirow{3}{*}{ Finite-element modal analysis $f(\mathrm{~Hz})$ (Reference) } \\
\hline & \multirow{2}{*}{ FDD $f(\mathrm{~Hz})$} & \multirow{2}{*}{$\operatorname{EFDD} f(\mathrm{~Hz})$} & \multicolumn{3}{|c|}{ SSI } & \\
\hline & & & UPC $f(\mathrm{~Hz})$ & PC $f(\mathrm{~Hz})$ & CVA $f(\mathrm{~Hz})$ & \\
\hline 1 & 3.125 & - & 3.30 & 3.30 & 3.30 & 3.24 \\
\hline 2 & 21.68 & 21.69 & 21.71 & 21.14 & 21.70 & 21.75 \\
\hline 3 & 68.36 & 68.26 & 68.22 & - & 68.20 & 68.22 \\
\hline 4 & 140.8 & 140.5 & 140.1 & - & 140.2 & 140.25 \\
\hline
\end{tabular}

TABLE 11: Identified damping ratio for Case 2.

\begin{tabular}{|c|c|c|c|c|c|c|}
\hline \multirow{3}{*}{ Mode } & \multicolumn{5}{|c|}{ Output-only PULSE methods } & \multirow{3}{*}{ Finite-element modal analysis $\xi(\%)$ (Reference) } \\
\hline & \multirow{2}{*}{$\operatorname{FDD} \xi(\%)$} & \multirow{2}{*}{$\operatorname{EFDD} \xi(\%)$} & \multicolumn{3}{|c|}{ SSI } & \\
\hline & & & UPC $\xi(\%)$ & $\mathrm{PC} \xi(\%)$ & CVA $\xi(\%)$ & \\
\hline 1 & - & - & 2.0 & 2.0 & 2.7 & 2.0 \\
\hline 2 & - & 1.85 & 2.0 & 1.9 & 2.0 & 2.0 \\
\hline 3 & - & 1.80 & 2.0 & - & 2.0 & 2.0 \\
\hline 4 & - & 1.60 & 2.0 & - & 2.0 & 2.0 \\
\hline
\end{tabular}

TABLE 12: Identified natural frequencies for Case 3.

\begin{tabular}{|c|c|c|c|c|c|c|}
\hline \multirow{3}{*}{ Mode } & \multicolumn{5}{|c|}{ Output-only modal testing methods } & \multirow{3}{*}{ Finite-element modal analysis $f(\mathrm{~Hz})$ (Reference) } \\
\hline & \multirow{2}{*}{$\operatorname{FDD} f(\mathrm{~Hz})$} & \multirow{2}{*}{$\operatorname{EFDD} f(\mathrm{~Hz})$} & \multicolumn{3}{|c|}{ SSI } & \\
\hline & & & $\mathrm{UPC} f(\mathrm{~Hz})$ & $\mathrm{PC} f(\mathrm{~Hz})$ & CVA $f(\mathrm{~Hz})$ & \\
\hline 1 & 3.3 & - & 3.30 & 3.30 & 3.30 & 3.24 \\
\hline 2 & 21.68 & - & 21.75 & 21.64 & 21.74 & 21.75 \\
\hline 3 & 68.55 & - & 68.22 & 68.90 & 68.22 & 68.22 \\
\hline 4 & 140.6 & - & 140.3 & 139.4 & 140.3 & 140.25 \\
\hline \multicolumn{7}{|c|}{ TABLE 13: Identified damping ratio for Case 3.} \\
\hline \multirow{3}{*}{ Mode } & \multicolumn{5}{|c|}{ Output-only PULSE methods } & \multirow{3}{*}{ Finite-element modal analysis $\xi(\%)$ (Reference) } \\
\hline & $\mathrm{FDD} \xi(\%)$ & FFDD $\xi(\%)$ & & SSI & & \\
\hline & FDD $\zeta(\%)$ & ЕFDD $\zeta(\%)$ & UPC $\xi(\%)$ & $\mathrm{PC} \xi(\%)$ & CVA $\xi(\%)$ & \\
\hline 1 & - & - & 2.0 & 2.0 & 2.0 & 2.0 \\
\hline 2 & - & - & 2.0 & 1.8 & 2.0 & 2.0 \\
\hline 3 & - & - & 2.0 & 1.6 & 2.0 & 2.0 \\
\hline 4 & 一 & - & 2.0 & 1.8 & 1.9 & 2.0 \\
\hline
\end{tabular}


some methods may be attributed to the fact that only few seconds, that is, 4 to 5 seconds of nodal responses have been used to identify modal parameters. The real damping ratios can easily be identified by comparing the damping ratios identified using different methods. It should also be noted that unlike UPC and CVA approaches, PC approach is not able to estimate modal parameters. Although these three methods are similar, their algorithms have different weighting functions. CVA usually performs better for loworder excited modes and may not provide information for higher-order modes if they are not properly excited.

Mode shapes identified using output-only modal testing methods match very well with simulation results using classical FRF-based modal analysis approach.

4.2. Extracted Modal Parameters Based on Case 2. The extracted natural frequencies of the solar panel using PULSE output-only modal testing techniques for Case 2 are given in Table 10. The identified damping ratios for Case 2 are also provided in Table 11.

Again the identified natural frequencies and damping factors are in close agreement with those obtained using finite-element modal analysis. Similar to Case 1, in this case FDD method cannot find the damping factors of the structure, while EFDD and SSI methods were almost able to identify damping factors for the first four modes. As it can be observed using acceleration nodal responses of only four nodes, it is possible to capture the modal parameters using output-only modal testing techniques.

4.3. Identified Modal Parameters Based on Case 3. The extracted natural frequencies and damping factors of the solar panel based on nodal responses at node 5 are given in Tables 12 and 13, respectively.

It is interesting to note that even using acceleration nodal responses of one node (node 5), natural frequencies and damping factors could be captured using output-only PULSE methods. Although FDD cannot identify the damping factor and EFDD was not able to find both natural frequencies and damping factors, SSI method could accurately provide both natural frequencies and modal damping factors.

It is found that the modal parameters identified for all the three cases have good agreement with the finite-element results. Usually, in real cases, only a few nodal responses are recorded and processed as done in the present study. It is shown that natural frequencies and damping ratios can be identified even by using nodal response at a single node. However, some optimization in the number and location of nodal responses is required to minimize the errors in identification.

\section{Conclusions}

In this work both analytical studies and output-only modal testing are conducted on an on-orbit satellite appendage in order to demonstrate the potential application of the outputonly modal testing method to effectively extract modal parameters. First an experimental and analytical study has been conducted on a simple plate structure under different operating excitations to identify its modal parameters using different output-only modal testing approaches. Finally the solar panel of the Communication Technology Satellite (CTS) has been simulated under representative operating excitation provided by the spacecraft thrusters to find its modal parameters using different output-only modal testing techniques. The results are also compared with those obtained using traditional modal analysis. It is aimed to demonstrate the potential application of output-only testing in satellite appendages. It is concluded that output-only modal testing based on SSI techniques could capture the modal parameters well using only a few nodal responses, which is very important in satellite and space applications.

\section{References}

[1] J. S. Bendat and A. G. Piersol, Engineering Applications of Correlation and Spectral Analysis, John Wiley \& Sons, New York, NY, USA, 1993.

[2] S. R. Ibrahim and E. C. Milkulcik, "A time domain modal vibration test technique," Shock and Vibration Bulletin, vol. 43, no. 4, pp. 21-37, 1973.

[3] S. R. Ibrahim and E. C. Milkulcik, "The experimental determination of vibration parameters from time response," Shock and Vibration Bulletin, vol. 46, no. 5, pp. 187-196, 1976.

[4] S. R. Ibrahim and E. C. Milkulcik, "A method for the direct identification of vibration parameters from the response," Shock and Vibration Bulletin, vol. 47, no. 4, pp. 183-198, 1977.

[5] H. Vold, J. Kundrat, and G. T. Rocklin, "A multi-input modal estimation algorithm for mini-computers," SAE Technical Paper 820194, International Congress and Exposition, Detroit, Mich, USA, 1982.

[6] H. Vold and G. T. Rocklin, "The numerical implementation of a multi-input modal estimation method for mini-computers," in Proceedings of the 1st International Modal Analysis Conference \& Exhibit (IMAC '82), pp. 542-548, Orlando, Fla, USA, November 1982.

[7] J.-N. Juang and R. S. Pappa, "An eigensystem realization algorithm for modal parameter identification and model reduction," Journal of Guidance, Control, and Dynamics, vol. 8, no. 5, pp. 620-627, 1985.

[8] J. N. Juang and R. S. Pappa, "Galileo Spacecraft Modal identification using an eigensystem realization algorithm," NASA AIAA-1984-1070, Structures and Dynamics Division, NASA Langley Research Center, Hampton, Va, USA, 1984.

[9] J. E. Cooper and J. R. Wright, "Spacecraft in-orbit identification using eigensystem realization methods," Journal of Guidance, Control, and Dynamics, vol. 15, no. 2, pp. 352-359, 1992.

[10] K. Fukuzono, Investigation of multiple reference Ibrahim time domain parameter estimation technique, M.S. thesis, Department of Mechanical \& Industrial Engineering, University of Cincinnati, Cincinnati, Ohio, USA, 1986.

[11] L. Zhang, R. Brincker, and P. Andersen, "A unified approach for two-stage time domain modal identification," in Proceedings of the International Conference on Structural Dynamics Modeling, Test, Analysis, Correlation, and Validation, Madeira Island, Portugal, June 2002.

[12] P. Van Overschee and B. De Moor, Subspace Identification for Linear Systems: Theory, Implementation and Applications, 
Kluwer Academic Publishers, Dordrecht, The Netherlands, 1996.

[13] P. Van Overschee and B. De Moor, "Subspace algorithms for the stochastic identification problem," Automatica, vol. 29, no. 3, pp. 649-660, 1993.

[14] P. Van Overschee and B. De Moor, "N4SID: subspace algorithms for the identification of combined deterministicstochastic systems," Automatica, vol. 30, no. 1, pp. 75-93, 1994.

[15] P. Van Overschee and B. De Moor, "A unifying theorem for three subspace system identification algorithms," Automatica, vol. 31, no. 12, pp. 1853-1864, 1995.

[16] S. M. Pandit, Modal and Spectrum Analysis: Data Dependent Systems in State Space, John Wiley \& Sons, New York, NY, USA, 1991.

[17] B. Peeters and G. De Roeck, "Reference-based stochastic subspace identification for output-only modal analysis," Mechanical Systems and Signal Processing, vol. 13, no. 6, pp. 855-878, 1999.

[18] B. Peeters and G. De Roeck, "Stochastic system identification for operational modal analysis: a review," Journal of Dynamic Systems, Measurement and Control, vol. 123, no. 4, pp. 659667, 2001.

[19] J. Lardies, "Detection of mechanical changes in vibration systems," in Proceedings of the 13th International Modal Analysis Conference, vol. 2460 of Proceedings of SPIE, pp. 10571062, Nashville, Tenn, USA, February 1995.

[20] J. Lardies, "Modal parameter identification from output-only measurements," Mechanics Research Communications, vol. 24, no. 5, pp. 521-528, 1997.

[21] W.-X. Rent and Z.-H. Zong, "Output-only modal parameter identification of civil engineering structures," Structural Engineering and Mechanics, vol. 17, no. 3-4, pp. 429-444, 2004.

[22] R. Brincker, L. Zhang, and P. Andersen, "Modal identification of output-only systems using frequency domain decomposition," in Proceedings of the European COST F3 Conference on System Identification and Structural Health Monitoring, pp. 273-282, Madrid, Spain, June 2000.

[23] R. Brincker, C. E. Ventura, and P. Andersen, "Why outputonly modal testing is a desirable tool for a wide range of practical applications," in Proceedings of the 21st International Modal Analysis Conference on Structural Dynamics, pp. 1-8, Kissimmee, Fla, USA, February 2003.

[24] R. Brincker and P. Andersen, "A way of getting scaled mode shapes in output-only modal testing," in Proceedings of the 21st International Modal Analysis Conference on Structural Dynamics, pp. 141-145, Kissimmee, Fla, USA, February 2003.

[25] M. Abdelghani, M. Goursat, T. Biolchini, L. Hermans, and H. van der Auweraer, "Performance of output-only identification algorithms for modal analysis of aircraft structures," in Proceedings of the 17th International Modal Analysis Conference (IMAC '99), vol. 1, pp. 224-230, Kissimmee, Fla, USA, February 1999.

[26] P. Guillaume, P. Verboven, and S. Vanlanduit, "Frequencydomain maximum likelihood identification of modal parameters with confidence intervals," in Proceedings of the 23rd International Conference on Noise and Vibration Engineering (ISMA '98), pp. 955-962, Leuven, Belgium, September 1998.

[27] P. Guillaume, R. Pintelon, and J. Schoukens, "Frequency domain-a survey," in Proceedings of the ISMA 21 International Conference on Noise and Vibration Engineering, pp. 651658, Leuven, Belgium, 1966.
[28] W. Heylen, S. Lammens, and P. Sas, Modal Analysis Theory and Testing, Department Mechanical Engineering, Katholieke Universiteit Leuven, Leuven, Belgium, 1995.

[29] P. Verboven, Frequency domain system identification for modal analysis, Ph.D. thesis, University of Brussels, Brussels, Belgium, 2002.

[30] R. Pintelon and J. Schoukens, System Identification: A Frequency Domain Approach, IEEE Press, New York, NY, USA, 2001.

[31] P. Fortescue and J. Stark, Spacecraft Systems Engineering, John Wiley \& Sons, New York, NY, USA, 1991.

[32] J. R. Wertz and W. J. Larson, Space Mission Analysis and Design, Kluwer Academic Publishers, Dordrecht, The Netherlands, 3rd edition, 1999.

[33] D. Fraser, H. Kleespies, and C. Vasicek, Spacecraft Structure, Texas Space Grant Consortium, Austin, Tex, USA, 1991.

[34] F. R. Vigneron, A. Parthasarathy, and T. D. Harrison, "Analysis of the structural dynamics of a flexible solar array and correlation with ground-testing," in Proceedings of the AIAA/CASI 6th Communications Satellite System Conference, pp. 1-9, Ottawa, Canada, April 1976, AIAA paper no. 76-242.

[35] V. J. Modi and A. C. Ng, "Dynamics of interconnected flexible members in the presence of environmental forces: a formulation with applications," Acta Astronautica, vol. 19, no. 6-7, pp. 561-571, 1989.

[36] M. Alam, Modal characteristics of satellite appendages using on-orbit output-only modal testing, M.S. thesis, Concordia University, Montreal, Canada, 2007. 

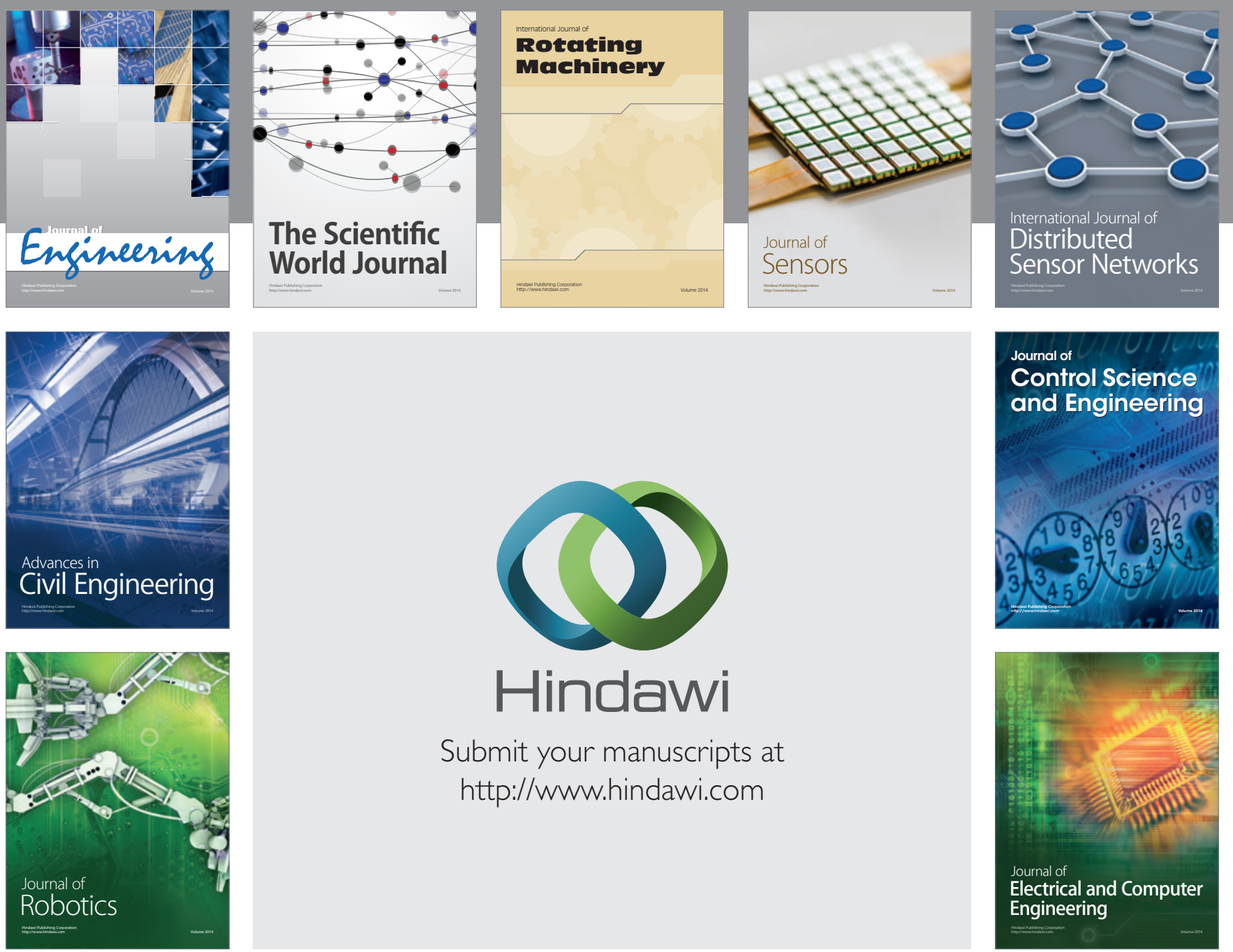

Submit your manuscripts at

http://www.hindawi.com
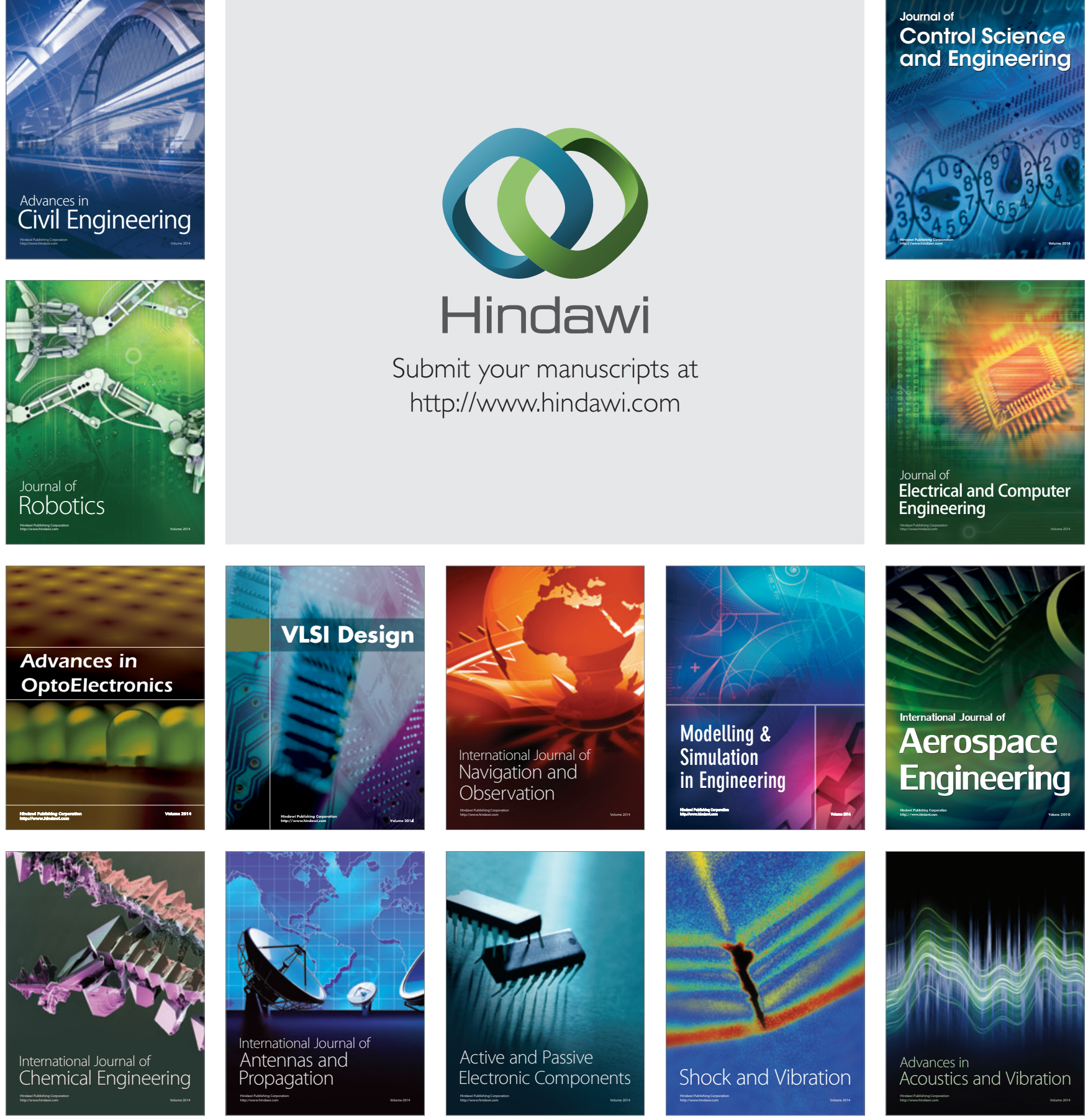